PNL-SA--19391

DE92 003001

\title{
COMPOSITE MATERIALS FOR FUSION APPLICATIONS
}
R. H. Jones
G. W. Hollenberg
C. H. Henager Jr.

.

October 1991

\section{Presented at the}

5 th International Conference on

Fusion Reactor Materials

October 21-25, 1991

Clearwater, Florida

Work supported by

the U.S. Department of Energy

under Contract DE-ACO6-76RLO 1830

Pacific Northwest Laboratory

Richland, Washington 99352<smiles>[C+]1[C+]=CC=C1</smiles>

\section{DISCLAIMER}

This report was prepared as an account of work sponsored by an agency of the United States Government. Neither the United States Government nor any agency thereof, nor any of their employees, makes any warranty, express or implied, or assumes any legal liability or responsibility for the accuracy, completeness, or usefulness of any information, apparatus, produci, or process disclosed, or represents that its use would not infringe privately owned rights. Reference herein to any specific commercial product, process, or service by trade name, trademark, manufacturer, or otherwise does not necessarily constitute or imply its endorsement, recommendation, or favoring by the United States Government or any agency thereof. The views and opinions of authors expressed herein do not. necessarily state or reflect those of the United States Government or any agcicy theieur. 


\section{COMPOSITE MATERIALS FOR FUSION APPLICATIONS}

Russell H. Jones, Charles H. Henager, Jr. and Glenn W. Hollenberg, Pacific Northwest Laboratory, Richland, Washington 99352

\section{Abstract}

Ceramic matrix composites, CMCs, are being considered for advanced first-wall and blanket structıral app?icätions because of their high-temperature properties, low neutron activation, low density and low coefficient of expansion coupled with good thermal conductivity and corrosion behavior. This paper presents a review and analysis of the hermetic, thermal conductivity, corrosion, crack growth and radiation damage properties of CMCs. It was concluded that the leak rates of a gaseous coolant into the plasma chamber or tritium out of the blanket could exceed design criteria if matrix microcracking causes existing porosity to become interconnected. Thermal conductivities of unirradiated $\mathrm{SiC} / \mathrm{SiC}$ and $\mathrm{C} / \mathrm{SiC}$ materials are about $1 / 2$ to $2 / 3$ that of Type 316 SS whereas the thermal conductivity for $c / C$ composites is seven times larger. The thermal stress figure-of-merit value for CMCs exceeds that of Type 316 SS for a single thermal cycle. SiC/SiC composites are very 
resistant to corrosion and are expected to be compatible with He or $L i$ coolants if the $0_{2}$ concentrations are maintained at the appropriate levels, CMCs exhibit subcritical crack growth at elevated temperatures and the crack velocity is a function of the corrosion conditions. The radiation stability of CMCs will depend on the stability of the fiber, microcracking of the matrix, and the effects of gaseous transmutation products on properties.

\section{Introduction}

Composite materials are ueing considered for a number of applications in fusion reactors including high heat flux surfaces, divertor structures, and first walls. In principle, composite materials are more "engineerable" than conventional meta?lic and ceramic materials because they need not rely on equilibrium phases for reinforcement. Therefore, there is greater freedom to optimize their properties to meet the many challenging requirements presented by fusion reactor environments.

Metal matrix composites (MMCs) assembied from metallic matrices and particulate, whisker, or fiber shaped ceramic reinforcements are extensions of dispersion hardened materials made by mechanical alloying. Kohyama et al. $(1,2)$ 
have evaluated the radiation response of $\mathrm{Al} / \mathrm{SiC}$ and $\mathrm{Al} / \mathrm{C}$ composite materials because of their potential for low activation and high temperature performance. They observed an increase in fracture strength for $\mathrm{Al} / \mathrm{SiC}$ materials at a fast neutron fluence of $10^{25} \mathrm{n} / \mathrm{m}^{2}$ at $723 \mathrm{~K}$ followed by a decrease at higher fluences. The strength response of these materials followed directly that of the fibers, as determined from extracted fibers and was related to radiation-enhanced crystallization of the amorphous Nicalon fibers. $\mathrm{Cu} / \mathrm{C}$ composites are also being evaluated by Zinkle et a1. (3) for divertor structural applications because of their thermal and mechanical properties. Radiation experiments are in progress.

Carbon/carbon composites are attractive for high-heat flux surfaces because of their high thermal conductivity (100 $\mathrm{W} / \mathrm{m}-\mathrm{K})$ in a direction perpendicular to the fibers in $3-D$ and 4-D C/C composites (4). In-directions parallel to the fibers, conductivity as high as $500 \mathrm{~W} / \mathrm{m}-\mathrm{K}$ has been obtained for 1-D C/C composite materials. This conductivity is important for minimizing thermal stresses, but heat removal depends on through-thickness conductivity. For comparison, copper has a conductivity of around $400 \mathrm{~W} / \mathrm{m}-\mathrm{k}$ at $25^{\circ} \mathrm{C}$. Radiation effects and thermal shock studies of $C / C$ composites are in progress $(5,6)$. 
Other low activation CMCs that are being evaluated for highheat flux and structural applications include C/SiC (graphite fibers in a SiC matrix), SiC/C and SiC/SiC (SiC fibers in graphite and SiC matrices). These materials offer a range of physical and mechanical properties because of variable fiber and matrix properties and fiber architectures. Although MMCs are being evaluated for selected fusion applications, the emphasis of this paper is to compare the properties of CMCS and issues regarding their potential applications in fusion reactors.

\section{Property Comparisons for Ceramic Composites}

Continuous fiber composites reinforced with graphite or SiC fibers are produced with 1-D to n-D fiber architecture prepared from woven, knitted, or braided fibers. Most of the materials that are compared in this paper are simple 2-D composites with a $0 / 90^{\circ}$ alignment. Although the properties become more isotropic with increasing dimensionality, the properties in the principal directions are usually diminished.

The properties of continuous fiber composites with about $40 \%$ graphite or SiC fibers are compared in Table 1. The graphite fibers are T-300 while the SiC fibers are Nicalon.(a) These are the highest strength versions of 
these respective fibers. The properties of $\mathrm{C}$ and $\mathrm{SiC}$ composites are also compared to Type 316 SS, although it is recognized that some of these comparisons are not strictly valid. The physical properties of the composite materials are relatively similar with the exception of $C / C$ where the density and coefficient of expansion are the lowest and the thermal conductivity is the highest. The thermal conductivity reported in Table 1 for $C / C$ is the highest reported value for this material; earlier reported values were as low as $10 \mathrm{~W} / \mathrm{m}-\mathrm{K}$ for the same orientation. The $\mathrm{C}$ and SiC reinforced materials are much less dense and have lower coefficients of expansion than Type 316 SS, but the specific heat and thermal conductivity of the $\mathrm{C} / \mathrm{SiC}$ and $\mathrm{SiC} / \mathrm{SiC}$ composite materials are quite similar to that of Type 316 SS.

The mechanical property comparisons made in Table 1 are only usefut for making qualitative comparisons since these parameters have different significance in CMCs and metallic materials. The SiC/SiC material has a similar modulus to that of Type 316 SS while the other materials all have lower modulii. The tensile strength in the CMCs refers to the ultimate stress following matrix microcracking and at the onset of significant crack extension, whereas the tensile strength in metallic materials refers to the ultimate stress

(a) Nicalon is a registered trademark of Nippon Carbon Company, Ltd., Japan and distributed by Dow Corning Corp. in the U.S. 
following plastic flow and the onset of plastic instability. Although the physical processes which establish the tensile strength in CMCs and metallic materials are fundamentally different, the effect is somewhat similar. Therefore, the comparisons in Table 1 reveal that Type 316 SS has a tensile strength ranging between a factor of 2 to 3 greater than that of the $\mathrm{C}$ and SiC materials. Of the CMCs, the $C / C$ material has the highest tensile strength while the $\mathrm{SiC} / \mathrm{SiC}$ the lowest. This property is very amenable to "engineering" with the use of different fibers, fiber volume fraction, or fiber architecture so this trend could easily be reversed.

The interlaminar shear strength is a property that is significant for multi-ply materials such as the $2-D, 0 / 90^{\circ}$ CMCs but is not a relevant parameter for metallic materials. For the CMC materials, those with SiC fibers have the highest interlaminar shear strengths but the differences are not great. Likewise, the fracture toughness values reported for ihe CMCs and Type 316 SS do not have equal significance for designing a component. The $K_{I c}$ values listed in Table 1 illustrate that the CMCs have sufficient toughness so that in the unirradiated condition, the first wall and blanket (FWB) vill be relatively flaw-insensitive as would a FWB built of Type 316 SS. Of course, the effects of multi-axial stresses, joining and radiation on these parameters must be considered for a rigorous assessment of these materials. 


\section{Structural Applications of Ceramic Composites}

The use of SiC as a low activation, first wall material was recommended several years ago by Hopkins et a1. (7). More recent7y, the ARIES I design was based on the use of SiC/SiC composite material for the divertor and first wall (8). Operating temperatures were in the range of 800 to $1000^{\circ} \mathrm{C}$ with a He coolant. A recent DOE workshop (9) was held to identify the potential feasibility issues in the structural applications of CMCs in fusion reactors. The following sections will review these issues and the status of our knowledge regarding these issues.

\section{Feasibility Issues}

The emphas is of the DOE workshop (9) was to identify key issues in the use of CMCs for fusion applications. This implies that there are other issues which were not addressed. These issues were not deemed unique to fusion but are generic to the CMC technology as a whole. The cost of material, scale-up, and other factors are issues which fall in this category. The issues identified by this workshop include: 1) hermeticity, 2) thermal conductivity, 3) chemical compatibility with coolant and blanket materials, 4) radiation stability, 5) joining, 6) thermal fatigue and thermal shock resistance, and 7) redefinition of 
design codes for brittle matrix-fiber strengthened materials.

\section{Hermetic Properties of Ceramic Composites}

Ceramic matrix composites made by the chemical vapor infiltration (CVI) technique generally contain $10-15 \%$ irorosicy, as shown by the micrographs for a SiC/SiC composite in Figure 1. If CMCs are to function as a pressure boundary, the coolant leak rate into the plasma and the tritium leak rate out of the blanket will be a major design criteria. Ceramic composites made by the CVI process retain more porosity than those made by hot-pressing or the DuPont-Lanxide Composites DIMOX(b) process but continuous fiber composites that exhibit the highest fracture toughnesses are made primarily by the CVI process.

The porosity retained by the CVI process is not interconnected, as shown in Figure $1 b$, because the porosity results from closure between adjacent fibers occurring during the matrix CVI process. Therefore, in the unirradiated condition, CMCS are expected to contain closed porosity. This will need to be verified, since some of the porosity may indeed interconnect. Also, the pores may become interconnected with the application of stresses above the matrix microcracking stress, or by creep, and

(b) Tradename of the DuPont-Lanxide Composites Corp. 
irradiation induced microcracking. Therefore, the pores may in fact interconnect with time and allow a pathway for gas leakage.

Jones (10) estimated the leak rate of He through a structure such as that shown in Figure 1 by using a gas flow equation for molecular flow through small orifices. Similar calculations have been performed previously (11) and compared to experimentally measured values for creep cracks in austenitic stainless steel. The agreement between measured and calculated values was quite good for flaws that were similar in size to those shown in Figure 1.

The limiting leak rate established in a study by Jones, Conn and Schaffer (11) ranges between $10^{-1}$ moles/s for a UWMAK II design to $4 \times 10^{-3} \mathrm{moles} / \mathrm{s}$ for a NUMAK reactor design. An upper bound value for the leak rate through a CMC was estimated by Jones (10) by assuming that ihe interconnection between all of the pores opened by creep to a valcie equal to the average pore size, $8 \times 100 \mu \mathrm{m}$. Assuming the entire first wall is made of SiC/SiC and utilizing the pore density data obtained from micrographs, such as Figure la, an upper bound leak rate of $7 \times 10^{5}$ moles $/ \mathrm{s}$ was determined. An alternative approach was to estimate the extent of opening between the pores that would produce the $10^{-1}$ moles/s 1 imit. An opening of only $0.3 \mathrm{~nm}$ was required if 211 of the pores 
were connected. In reality, not all of the pores will become interconnected by microcracking or creep, but the calculated leak rates suggest that the poor hermetic properties of CMCs might require using a seal coat or metallic liner to reduce the coolant in-leakage or the tritium out-leakage to an acceptable lever.

\section{Thermal Conductivity of Ceramic Composites}

Thermal conductivity is important for minimizing the stress in a material exposed to a thermal gradient and for removing heat from energy conversion systems. The thermal conductivity of CMCs are generally less than their monolithic counterparts because of the high density of fiber/matrix interfaces and the higher porosity. Examples of the thermal conductivity for graphite and $C / C$ composites is shown in figure $2 \mathrm{a}(4)$ and examples of the thermal conductivity for $\mathrm{SiC} / \mathrm{SiC}$ composites is shown in Figure $2 \mathrm{~b}$ (12). The $]-D, 2-D$, and 3-D [Z] values are for in-plane thermal conductivity, while the 4-D, 3-D [X] is throughthickness thermal conductivity. The through-thickness value for a $3-D C / C$ composite is about a factor of ten less than that for monolithic graphite. At $1000^{\circ} \mathrm{C}$, the throughthickness thermal conductivity is about $35 \mathrm{~W} / \mathrm{m}-\mathrm{K}$ for $\mathrm{C} / \mathrm{C}$ and about $6 \mathrm{~W} / \mathrm{m}-\mathrm{K}$ for $\mathrm{SiC} / \mathrm{SiC}$. Westwood and Notis (13) reported the thermal conductivity of single crystal $\mathrm{SiC}$ as $90 \mathrm{~W} / \mathrm{m}-\mathrm{K}$ 
at 25 to $150^{\circ} \mathrm{C}$ while $\mathrm{Be} 0$ doped SiC had a thermal

conductivity of $270 \mathrm{~W} / \mathrm{m}-\mathrm{K}$ at $25^{\circ} \mathrm{C}$ (7) and high-purity single crystal SiC a conductivity of $490 \mathrm{~W} / \mathrm{m}-\mathrm{K}(14)$. Thermal conductivity of polycrystalline $\mathrm{SiC}$ is a function of impurity content, processing method, etc. but has been reported as being between 12 to $35 \mathrm{~W} / \mathrm{m}-\mathrm{K}$.

There $i:$ no data on thermal conductivity of irradiated CMCs, although there is data for monolithic SiC irradiated to $10^{26}$ $\mathrm{n} / \mathrm{m}^{2}$ at ine test temperatures shown in Figure $2 \mathrm{~b}(7)$. The thermal conductivity decreased from 25 to $12 \mathrm{~W} / \mathrm{m}-\mathrm{K}$, when irradiated at $1000^{\circ} \mathrm{C}$ and from 37 to $9 \mathrm{~W} / \mathrm{m}-\mathrm{K}$, at $500^{\circ} \mathrm{C}$. The ARIES I design temperature for $\mathrm{SiC} / \mathrm{SiC}$ was between 800 to $1000^{\circ} \mathrm{C}$, so a decrease of a factor of 2 to 3 would be expected after a fluence of $10^{26} \mathrm{n} / \mathrm{m}^{2}$. Whether the conductivity will continue to decrease with increasing fluence and the response of CMCS is unknown and will need to be determined before a fusion reactor can be designed and built with CMCs.

Improvements in the thermal conductivity are, in principle, possible with CMCS because of the "engineerable" aspect of these materials. Han and Cosner (15) have modeled the thermal conductivity of fiber reinforced composite materials with the results shown in Figure 3 for a $0 / 90^{\circ} 2-D$ composite with a staggered fiber arrangement and a unit cell of $b / a=$ 
2. The through-thickness effective conductivity, $K_{e}$, normalized by the matrix value, $K_{m}$, is shown in Figure $3 a$ relative to $\beta$, the ratio of the fiber conductivity, $K_{f}$, to $K_{m}$. Similar values are given for the in-plane conductivity in Figure $3 \mathrm{~b}$. These calculations indicate that the throughthickness conductivity can be doubled for a $\beta$ value of 10 and a volume fraction $\left(V_{f}\right)$ of $40 \%$ and increased by a factor of 4 for a $\beta$ of 10 and a volume fraction of $70 \%$. The inplane conductivities would increase by more than a factor of 4 for similar $\beta$ and $V_{f}$ values. Much larger increases in the in-plane conductivity are possible with increasing values of $\beta$ than for through-thickness conductivities that clearly reach limiting values at $\beta$ between 10 to $\$ 00$. A C/SiC composite would be expected to have a through-thickness conductivity of 12 and $24 \mathrm{~W} / \mathrm{m}-\mathrm{K}$ for a $\mathrm{V}_{\mathrm{f}}$ of $40 \%$ and $70 \%$, respectively. Increases in the conductivity of the $C / C$ and SiC/SiC composites should be limited because the ratio of $K_{f} / K_{m}$ is probably less than 1 .

A thermal stress figure-of-merit derived for a range of materials has been reported by Whitley (16) as shown in Figure 4. The figure-of-merit value depends on thermal conductivity, yield strength, elastic modulii. and the coefficient of therma? expansion. Large values suggest a material that can tolerate higher heat loads; however, materials that undergo microc, acking may have a high value 
for a single thermal cycle but could be degraded more rapidly with thermal cycling than materials that deform plastically. Clearly, $\mathrm{C} / \mathrm{C}$ and graphite materials have the highest figure-of-merit values for a single thermal cycle; while $\mathrm{SiC} / \mathrm{SiC}$ and $\mathrm{C} / \mathrm{SiC}$ have much lower values, as indicated in Figure 4 and Table 1. Type 316 SS has the lowest value of the metallic materials.

\section{Chemical Compatibility Issues}

Most ceramics are chemically stable and resistant to corrosion in many environments. Ceramic matrix composites are expected to also exhibit similar corrosion resistance; liowever, the stability of the fiber and interface may differ from monolithic ceramics and the method of manufacturing CMCs, i.e. CVI, can result in a relatively porous matrix that does not protect the fibers from the environment. of particular concern, is the fiber/matrix interface through which CMCs gain their strength and toughness. Also, subcritical crack growth of cracks in CMCs is accompanied by the development of a bridging zone of fibers behind the crack. Exposure of these fibers and fiber/matrix interfaces to a corrosive environment could alter the subcritical crack growth hehavior of CMCs, as demonstrated by the subcritical crack growth data presented in this paper. 


\section{Corrosion of Ceramic Composites}

Ceramic composites used for structural applications in fusion reactors will require compatisility with coolants and blanket materials. Potential reactants include $\mathrm{O}_{2}, \mathrm{H}_{2}, \mathrm{H}_{2} \mathrm{O}$ in a He coolant, $L i$ in an $L i$ cooled system or from $L i$ ceramics used for breeding $T$ and Be used as a neutron multiplier. Compatibility with the impurities in a $\mathrm{He}$ coolant might be a concern because of the large mass flow of impurities in flowing He.

Silicon carbide is thermodynamically unstable in $\mathrm{O}_{2}, \mathrm{H}_{2}$ and $\mathrm{H}_{2} \mathrm{O}$ environments and will react with them in the following manner:

$$
\begin{gathered}
\mathrm{SiC}(\mathrm{s})+\mathrm{O}_{2}(g)=\mathrm{SiO}(g)+\mathrm{CO}(g): \operatorname{LOW} \mathrm{PO}_{2} \text { (1a) } \\
\mathrm{SiC}(\mathrm{s})+3 / 2 \mathrm{O}_{2}(g)=\mathrm{SiO}_{2}(\mathrm{~s})+\mathrm{CO}(g): \mathrm{High} \mathrm{PO}_{2}^{(1 \mathrm{~b})} \\
\mathrm{SiC}(\mathrm{s})+2 \mathrm{H}_{2}(g)=\mathrm{si}+\mathrm{CH}_{4}(g) \\
\operatorname{SiC}(\mathrm{s})+2 \mathrm{H}_{2} \mathrm{O}(g)=S i O(g)+\mathrm{CO}(g)+2 \mathrm{H}_{2}(g)
\end{gathered}
$$

The stability of SiC depends on the formation of a stable "passive" layer of $\mathrm{SiO}_{2}$ with the active-passive oxidation behavior described by Figure 5 (17). Active oxidation of 
SiC occurs at around $10^{-8}$ atm of $0_{2}$ at $900^{\circ} \mathrm{C}$, which is with in the ARIES I temperature range. Obviously, it would be advantageous to maintain an adequate $0_{2}$ partial pressure in the He coolant to maintain SiC-based CMCs in the "passive" oxidation regime. 0xidation of $\mathrm{C}$ to $\mathrm{CO}$ or $\mathrm{CO}_{2}$ is a concern for $\mathrm{C} / \mathrm{C}$ and $\mathrm{C} / \mathrm{SiC}$ as well as for $\mathrm{SiC} / \mathrm{SiC}$ composites relying on a $C$ interfacial layer for fracture toughness. An example of the oxidation resistance of uncoated $\mathrm{SiC} / \mathrm{C}$ and $\mathrm{C} / \mathrm{C}$ composites at $815^{\circ} \mathrm{C}$ is shown in Figure 6. Nicalon was the fiber used in the $\mathrm{SiC} / \mathrm{C}$ composite and presumably a layer of $\mathrm{SiO}_{2}$ may have formed to protect this composite even though the matrix was $C$. The instability of $\mathrm{C} / \mathrm{C}$ type composites in an oxidizing atmosphere is clearly demonstrated by this data.

Hydrogen or tritium will be present in the He coolant if He is used as a sweep gas in the $T$ breeding blanket, from outleakage from the plasma or from out-gassing from materials in which it is generated by $(n, p)$ reactions. Therefore, the stability of CMCs in $\mathrm{He} / \mathrm{H}_{2} / \mathrm{H}_{2} \mathrm{O}$ mixtures is also important. Jacobson, Eckel, Misra and Humphrey (18) have calculated the stability of $\mathrm{SiC}$ in an $\mathrm{Ar} / \mathrm{H}_{2} \mathrm{O} / 5 \% \mathrm{H}_{2}$ mixture with the results shown in Figure 7. Though these calculations are for a temperature about $300^{\circ} \mathrm{C}$ above that expected for a fusion reactor blanket constructed out of CMCs, it does illustrate some of the potential reactions. SiC could react with a 
$\mathrm{He} / \mathrm{H}_{2} / \mathrm{H}_{2} \mathrm{O}$ gas mixture to form $\mathrm{CO}, \mathrm{CH}_{4}$, and $\mathrm{SiO}$ gaseous products and all of these gaseous reaction products could be detrimental to the mechanical integrity of a $\mathrm{SiC} / \mathrm{SiC}$ structural blanket. These data illustrate that these reactions are thermodynamically possible without details regarding the kinetics of these reactions. Detailed chemical compatibility studies for the CMCs that are applicable to fusion reactors will be necessary to determine corrosion and subcritical crack growth rates.

CMCs can react with $\mathrm{Li}$ if $\mathrm{Li}$ is chosen as a coolant or from contact with Li ceramics used for $T$ breeding. The major reaction between alkali metals and $\mathrm{Si}$-based ceramics is the formation of a low melting temperature salt such as those shown by the $\mathrm{Li}_{2} \mathrm{O}-\mathrm{SiO}_{2}$ phase diagram in Figure 8. Eutectics at 1024 and $1028^{\circ} \mathrm{C}$ are relatively close to the potential operating temperature of a fusion reactor constructed with CMCs. Reaction with $\mathrm{SiO}_{2}$ is of concern because of its presence at grain boundaries and surfaces (i.e. reaction of $\mathrm{SiC}$ with $\mathrm{O}_{2}$ ). Degradation of the protective "passive" $\mathrm{SiO}_{2}$ layer and accelerated crack growth caused by the decreased viscosity of grain boundary glass phases in contact with alkali metals are two of the possible chemical compatibility concerns for $\mathrm{SiC} / \mathrm{SiC}$ composites in contact with a $\mathrm{Li}$ coolant or $L i$ ceramic. It is anticipated that the $L i$ coolant would be maintained at very low $\mathrm{O}_{2}$ activity, thus minimizing the 
possibility of forming the phases shown in Figure 8. However, this is not true with Li ceramics so it will be necessary to minimize contact between SiC and Li ceramics.

The corrosion and fracture behavior of SiC in molten $\mathrm{Li}$ has been evaluated by Curran and Amateau (19) and Cree and Amateau (20). Both studies were conducted on $\alpha$-SiC exposed to a thin layer of molten $L i$ in contact with the sample surface. A decrease in the room temperature fracture strength from about $350 \mathrm{MPa}$ to about $150 \mathrm{MPa}$ was found in both studies for exposures exceeding $500^{\circ} \mathrm{C}$. The strength loss was related to $\mathrm{Li}$ penetration down $\mathrm{SiC}$ grain boundaries. Reaction with the glass phase in the SiC grain boundaries was considered to be the primary cause of the rapid intergranular penetration. Uniform corrosion rates were reported as being extensive but with no apparent effect on the fracture strength. Cree and Amateau (20) found a bimodal distribution in the fracture strengths where the low strength group was related to intergranular $\mathrm{Li}$ penetration and the high strength group associated with the absence of grain boundary penetration. In the absence of intergranular penetration, the fracture strength decreased s?ightly with increasing exposure temperature to a value of about $300 \mathrm{MPa}$ after exposure at 800 and $1000^{\circ} \mathrm{C}$. 
Fracture toughness values were also reported by Curran and Amateau (19) using the direct-crack-measurement indentation method. The fracture toughness was determined from this method by measuring the crack length produced by indentation of the surface. This method is very sensitive to changes in the properties of the material near the surface and is subject to error associated with the compressive stresses created by the indentation process. The indentation fracture toughness measurements made by Curran and Amateau were sensitive to the effects of surface corrosion reactions. They observed a decrease in the room temperature fracture toughness from about $4 \mathrm{MPa} / \mathrm{m}$ to about $2 \mathrm{MPa} / \mathrm{m}$ following exposure to molten $\mathrm{Li}$ for $30 \mathrm{~min}$ at $600^{\circ} \mathrm{C}$. A 30-min exposure to $\mathrm{Ar}$ at $800^{\circ} \mathrm{C}$ caused a decrease to about 3 $M P a / m$, so the effects of $L i$ are not due solely to a corrosion reaction but also to changes in the properties of the near-surface material.

The studies by Curran and Amateau (19) and Cree and Amateau (20) were conducted for relatively short exposure periods of 30 to $60 \mathrm{~min}$. It was concluded in both studies that exposure time within these limits did not affect the properties; however, these exposure times are too short to suggest that further changes will not occur during extended fusion reactor operation. Also, the reported studies were conducted with the SiC exposed to a limited supply of liquid 
Li. Exposure to a flowing Li coolant would likely produce a higher corrosion rate because the corrosion rate would be expected to decrease as $\mathrm{Li}$ becomes saturated with $\mathrm{SiC}$ and $\mathrm{SiO}_{2}$.

\section{Subcritical Crack Growth of Ceramic Composites}

Subcritical crack growth in CMCs appears to be controlled by fundamentally different mechanisms compared to monolithic ceramics, with correspondingly different mechanical responses. Crack-wake bridging by long fibers in continuous fiber reinforced CMCs, which is responsible for the high fracture toughness of CMCs [19], dominates the mechanical response of these materials. Therefore, the time-dependent response of the bridging zone at elevated temperatures appears to be the dominant mechanism affecting subcritical crack growth in CMCs.

Experiments and micromechanical modeling conducted at PNL suggest that the bridging zone completely controls the mechanical response and subcritical crack growth rates in CMCs. Composites consisting of Nicalon(a) fiber cloth $(0 / 90)$ and CVI SiC with and without carbon in the interfaces are currently being studied. Stepped load tests with load holding un single-edge notched bend bars (SENB) conducted at 
$1100^{\circ} \mathrm{C}$ in argon and argon plus $2000 \mathrm{ppm} \mathrm{O}_{2}$ reveal a stage II regime in the $\mathrm{V}-\mathrm{K}$ data that does not appear in $\mathrm{V}-\mathrm{K}$ data for monolithic ceramics, Figure 9. For CMCs, the transition to power law crack growth, Stage III, occurs at large values of stress intensity near the value of $K_{Q}$ as determined from 4point bending tests of SENB specimens. At present, there is little evidence to suggest the presence of a stage I regime at low $\mathrm{K}$ values.

The evidence for bridging zone domination of subcritical crack growth comes partly from experiments using argon plus oxygen in comparison with pure argon and partly from the micromechanical model being developed for this work. The addition of $2000 \mathrm{ppm}$ oxygen to the $1100^{\circ} \mathrm{C}$ argon environment increases the crack velocity in the stage II regime and shifts the stage II-stage III transition to lower $K$ values, as shown in Figure 9. The shift to lower $k$ values for the transition to stage III crack growth is consistent with a reduction in the pinching forces imparted on the crack faces by the bridging fibers. SEM photomicrographs of the CMCS exposed to the $2000 \mathrm{ppm} 0_{2}$ plus argon reveal the partial removal of the carbon interfaces caused by direct oxidation at $1100^{\circ} \mathrm{C}$. The removal of this interface material can be expected to reduce the shear strength of the interface, the ability of the matrix to transfer load to the fibers, and the bridging zone crack-tip shielding effectiveness. This 
is demonstrated in the micromechanical model calculations shown in Figure 10. A bridged crack of a fixed bridging zone length is simulated numerically and the fiber pinch force is allowed to vary as shown. A reduction in the interfacial shear strength, $\tau$, would reduce the fiber pinching forces and shift the crack velocity to lower applied $K$ values, which agrees with our recent experimental findings.

It is not surprising that these $\mathrm{SiC} / \mathrm{SiC}(\mathrm{f})$ composites are sensitive to environmental effects since their mechanical response is dominated by the crack wake bridging zone that is completely exposed to the environment. Careful studies would be required to determine the effect of fusion environments on subcritical crack growth in CMCs. More severe environments that corrode the reinforcing fibers or the interfaces would be potentially very deleterious. In addition, radiation effects on CMCs would need to be factored into these studies. Differential matrix/fiber swelling, fiber/matrix interface dimensional and structural stability, fiber structural stability and fiber/matrix interface displacement mixing effects would all need to be determined for these materials.

Radiation Stability of Ceramic Composites 
Radiation effects data on SiC/SiC is virtually nonexistent and the amount of data on monolithic SiC is also very sparse. Dimensional stability of $\beta-\mathrm{SiC}$ as a function of fast neutron fluence and irradiation temperature has been reported by Price (22), Figure 11. The linear expansion at fusion relevant temperatures of less than $1000^{\circ} \mathrm{C}$ shows a maximum expansion of 1 ess than $0.2 \%$ at $625^{\circ} \mathrm{C}$ at a fluence of $2 \times 10^{25} \mathrm{n} / \mathrm{m}^{2}$ and a 7 inear expansion of about $0.1 \%$ at 900 $1050^{\circ} \mathrm{C}$ at a fluence of $10^{26} \mathrm{n} / \mathrm{m} 2$. Mechanical property data for irradiated material is not available at fusion-relevant temperatures, but at $650^{\circ} \mathrm{C}$ there is a minimum in both the elastic modulus and the fracture strength with some recovery of these properties at higher fluences. The fracture strength decreases from about $320 \mathrm{MPa}$ to about $220 \mathrm{MPa}$ at a fluence of $10^{25} \mathrm{n} / \mathrm{m}^{2}$, as shown in Figure 12 .

When developing CMCs for radiation resistance, we must consider the damage to the fiber, fiber/matrix interface and the matrix. High-temperature $\left(400-1200^{\circ} \mathrm{C}\right)$ radiation effects studies of $\mathrm{SiC} / \mathrm{SiC}$ composites are in progress at PNL and will be reported at a future time. At present, it is only possivle to list the potential effects of radiation on the physical and mechanical properties of these materials. For a Nicalon(a) fiber reinforced material, instability of the amorphous Nicalon(a) must be considered. Kohyama et al. (2) have measured the fracture strength of Nicalon(a) fibers 
extracted from an Al matrix following irradiation at $450^{\circ} \mathrm{C}$. There was an initial increase at a fluence of $10^{24}$ to $10^{25}$ $\mathrm{n} / \mathrm{m}^{2}$ followed by a decrease to about $75 \%$ of the unirradiated value at a fluence of $10^{26} \mathrm{n} / \mathrm{m}^{2}$. The loss in strength was related to crystallization of the amorphous fiber. It is expected that this crystallization will be accompanied by a volume contraction, whereas the $\beta$-SiC matrix would experience a smali $(<0.2 \%)$ but positive volume expansion at $10^{26} \mathrm{n} / \mathrm{m}^{2}$. These dimensional instabilities could cause two very important effects: 1) the contraction of the fiber away from the matrix and the consequent loss of load transfer capability and 2) microcracking of the matrix from residual stresses resulting from the differential dimensional changes of the fiber and the matrix. Microcracking of the matrix is likely to occur even without the stress imposed by fiber contraction. The reduction in the tensile modulus and fracture strength of monolithic SiC, Figure 12, is likely the result of microcracking while the recovery of these properties is likely the result of microcrack healing.

The probable effect of irradiation on the fracture toughness of $\mathrm{SiC} / \mathrm{SiC}$ is shown in Figure 13. The load-deflection response of continuous fiber composites exhibits a linear elastic region with deviation from linear elastic response, which results from matrix microcracking. Significant matrix and fiber bundle fracture determines the ultimate strength 
or fracture strength while continued fiber pul1-out behind the crack front results in deflections or strains exceeding $1 \%$. Monolithic SiC exhibits only the linear elastic response with a sudden load drop as the first crack begins to propagate. The strain to failure of monolithic SiC is on the order of $0.1 \%$. Contraction of the Nicalon(a) fibers and matrix microcracking is expected to produce a composite with a lower elastic modulus and fracture strength but with a significant fracture strain. It will be necessary to determine the limit to these effects with fluence and temperature before CMCS can be considered for structural applications. However, an irradiation response such as that shown in Figure 13 may be acceptable with appropriate design considerations.

Gaseous transmutation products, such as $H e$ and $H$, could have an effect on the mechanical properties of CMCs. The transmutation rates are summarized in Table 1 where it can be seen that the He generation rate is about 10 times that of Type 316 SS while the $H$ generation rate for SiC bearing materials is between $1 / 4$ to $1 / 2$ that of Type 316 SS. The values for $\mathrm{C} / \mathrm{SiC}$ and $\mathrm{SiC} / \mathrm{C}$ were estimated from that for $\mathrm{SiC} / \mathrm{SiC}$ assuming transmutation of only Si. The threshold for ${ }^{12} \mathrm{C}$ is $17 \mathrm{MeV}$ which is above the neutron energy from a $\mathrm{D}+\mathrm{T}$ reaction, therefore, the $\mathrm{H}$ transmutation rate was considered to be negligible for $C$. 
Transmutation of $\mathrm{C}$ to $\mathrm{He}$ in the SiC fibers and matrix will shift the composition away from stoichiometry and could produce damage within the microstructure depending on the location of the He. If $\mathrm{He}$ is sufficiently mobile it could accumulate in the porous regions without causing serious damage; however, accumulation within the lattice could assist void formation as it does with metallic materials. Loss of $\mathrm{C}$ from the amorphous $\mathrm{Si}-\mathrm{C}-\mathrm{O} \mathrm{NiCa}_{\mathrm{C}} \mathrm{n}^{\mathrm{TM}}$ fibers is probably not as detrimental as it will be in crystalline $\beta$ SiC. Experimental radiation damage studies must be conducted to fully characterize the response and guide the development of radiation resistant CMCs.

Low neutron activation of $\mathrm{SiC} / \mathrm{SiC}$ is considered one of its greatest benefits for fusion structural applications. Seki et al. (23) calculated the $\gamma$-ray intensity decay for a highpurity $\mathrm{C} / \mathrm{SiC}$ composite material containing only $200 \mathrm{ppm} \mathrm{Ca}$, Figure 14. Following an irradiation to $10 \mathrm{MW}-\mathrm{y} / \mathrm{m}^{2}$ a $\mathrm{C} / \mathrm{SiC}$ first wall reached a level of $2 \mathrm{mrem} / \mathrm{hr}$ after about 300 hours. The Ca concentration control led the decay time aithough the production of ${ }^{26} \mathrm{Al}$ from ${ }^{28} \mathrm{Si}$ and ${ }^{30} \mathrm{Si}$ resulted in a low-level decay lasting $10^{6} \mathrm{y}$. CMCs reinforced with Nicalon(a) which contains large quantities of 0 or other polymer-derived fibers such as the Tyranno or HPZ which contain $\mathrm{N}$ and 0 . The $\mathrm{N}$-containing fibers have better high temperature stability than Nicalon(a) and could also be more 
stable in an irradiation environment. Clearly, activation analysis must be conducted for material with the appropriate impurity concentration.

\section{Summary}

Ceramic matrix composites offer tremendous potentiai as structural materials for fusion applications. Hightemperature properties, low density, low thermal expansion and neutron activation are some of their positive attributes while hermeticity, radiation stability and joining are attributes that will need further research before CMCs are suitable for fusion structural applications can be made.

$\mathrm{SiC} / \mathrm{SiC}$ composites have densities that are about $1 / 4$ and coefficients of expansion about $1 / 5$ that of Type 316 SS whi?e their thermal conductivities and elastic modulii are similar. Though fracture strengths and fracture toughness of SiC/SiC are less than Type $316 \mathrm{SS}$ at $25^{\circ} \mathrm{C}$, the strength of SiC/SiC is relatively independent of temperature up to $1200^{\circ} \mathrm{C}$ while the strength of Type 316 SS decreases rapidly above about $400^{\circ} \mathrm{C}$.

Leak rates of a $\mathrm{He}$ coolant through $\mathrm{SiC} / \mathrm{SiC}$ into the plasma or $T$ out-leakage may meet design limits in the unirradiated condition but matrix microcracking and creep crack growth 
are expected to result in leak rates that exceed the tolerable limits. Experimental determination of these values is needed to assess the leak rates and to evaluate possible solutions if needed.

Thermal conductivities of $\mathrm{SiC} / \mathrm{C}$ and $\mathrm{C} / \mathrm{SiC}$ composites are comparable to those of Type 316 SS, though $C / C$ composites have thermal conductivities that are 7 times greater. Thermal conductivity coupled with strength, elastic and expansion properties determine a thermal stress factor where $\mathrm{SiC} / \mathrm{SiC}$ has a value about 2.5 times greater than Type 316 SS and $\mathrm{C} / \mathrm{C}$ a factor that is $10^{3}$ times larger because of the large thermal conductivity and low thermal coefficient of expansion of $\mathrm{C} / \mathrm{C}$. Radiation-induced microcracking is expected to reduce the thermal conductivity of these materials.

Chenical compatibility of $\mathrm{SiC} / \mathrm{SiC}$ composites should not be a factor for $\mathrm{He}$ or $\mathrm{Li}$ coolants if the $\mathrm{O}_{2}$ concentrations are appropriately controlled. Interaction with Li ceramics in the breeding blanket could be a concern because of low melting temperature silicates that could form. $C / C$ composites may require protective coatings in He coolants because of the oxidation of $C$. He coolants will likely contain some $\mathrm{H}_{2} \mathrm{O} / \mathrm{H}_{2}$ ratio as a result of $\mathrm{H}$ outgassing from the material or where $\mathrm{He}$ is used as a sweep gas to remove $\mathrm{T}$ 
from lithium ceramics. Large concentrations of $\mathrm{H}_{2}$ could destabilize the "passive" $\mathrm{SiO}_{2}$ 1ayer. Experimental corrosion measurements in simulated reactor coolants will be necessary to determine long-term chemical stability of CMCs in contact with fusion reactor coulants although corrosion does not look like a major concern.

Radiation stability of both $\mathrm{C} / \mathrm{C}$ and $\mathrm{SiC} / \mathrm{SiC}$ materials is an area where further research is necessary. Large dimensional changes have been noted for $C / C$ composite materials while $\mathrm{SiC} / \mathrm{SiC}$ materials are expected to be much more stable. Radiation induced contraction and loss of strength of Nicalon fibers in SiC/SiC composites could lead to decreased modulii and fracture strengths as well as matrix microcracking. Formation of $\mathrm{He}$ and $\mathrm{H}$ by nuclear transmutation and the consequent change in stoichiometry is al so a radiation stability issue which must be addressed but for which there is no existing data.

\section{Acknowledgements}

The assistance of S. M. Halazon in preparing the manuscript is gratefully acknowledged. This research was supported by the Office of Fusion Energy of the U.S. Department of Energy under contract DE-ACOE-76RL0 1830 with Battelle Memorial Institute. 


\section{References}

[1] A. Kohyama, H. Tezuka, N. Igata, Y. Imai, H. Teranish and T. Ishikawa, J. of Nucl. Matls., vol. 141-143 (1986) 96.

[2] A. Kohyama, S. Sato, H. Tezuka and M. Kondo, J. of Nuc1: Mat1s, Vol. 179-181, (1991) 254.

[3] S. Zinkle, private communication.

[4] R. B. Dinwiddie, J. W. Sapp and D. A. Bowers, 20th Biennial Conference on Carbon, June 24-28, 1991, Santa Barbara, CA., DOE CONF 910645-1.

[5] H. Takatsu, M. Seki, M. Araki, M. Yamamoto, K. Fukaya, M. Ogawa, M. Etoh, S. Yamasaki, S. Koga, and T. Kobayashi, J. of Nucl. Matls., Vol. 179-181 (1991) 344 .

[6] T. D. Burche11, in "Proceedings of the Office of Fusion Energy/DOE Workshop on Ceramic Matrix Composites for Structural Applications in Fusion Reactors," R. H. Jones and G. E. Lucas, eds., held in Santa Barbara, CA, May 21-22, 1990, PNL-SA-18743, CONF-9005225, p. 435. 
[7] G. R. Hopkins and J. Chin, J. of Nuclear materials, Vols 141-143 (1986) 148.

[8] C. P. C. Wong, E. T. Cheng, B. McQuillan, E. E. Reis, Jr., K. R. Schultz, S. P. Grotz, M. F. Hasan, R. Martin, F. Najmabaci, S. Sharafat, T. Kunngi, J. S. Herring, D. K. Sze and the Aries Team, "Aries-I SiC Composite Low Activation Blanket Design", Fusion Technology, Vol. 19 (1991) 938.

[9] "Proceedings of the Office of Fusion Energy/DOE Workshop on Ceramic Matrix Composites for Structural Applications in Fusion Reactors," R. H. Jones and G. E. Lucas, eds., held in Santa Barbara, CA, May 21-22, 1990, PNL-SA-17843, CONF-9005225

[10] R. H. Jones, "Gas Leak Rate Estimates for Ceramic Matrix Composites, "Fusion Reactor Materials Semiannual Progress Report for Period Ending September 30, 1991, DOE/ER-0313/11.

[11] R. H. Jones, R. W. Conn and R. F. Schaffer, "Effect of First Wall Flaws on Reactor Performance, "Nuclear Engineering and Design/Fusion, 2 (1985), 175. 
[12] P. J. Lamicq, G. A. Bernhart, M. M. Dauchier and J. G. Mace, "SiC/SiC Composite Ceramics", Am. Ceram. Soc. Bu11. 65 (1986) 336 .

[13] A. D. Westwood and M. R. Notis, JoM (June 1991) 10.

[14] CRC Handbook, of Chemistry and Physics, CRC Press West Palm Beach, FL, 59th Ed., p. E-5.

[15] L. S. Han and A. A. Cosner, J. of Heat Transfer, Vo1. 103 (1981) 387.

[16] J. Whitley, J. Nucl. Mater. Vol. 133 and 134(1985) 39.

[17] E. A. Gulbransen and S. A. Jansson, 0xid. Met., 4 (1972) 181 .

[18] N. S. Jacobson, A. J. Ecke1, A. K. Misra and D. L. Humphrey, J. Am. Ceram. Soc., 73 (1990) 2330.

[19] D. R. Curran and M. F. Amateau, Am. Ceram. Bu11., 65 (1986) 1419.

[20] J. W. Cree and M. F. Amateau, J. Am. Ceram. Soc., 70 (1987) C-318. 
[21] A. G. Evans, J. Am. Cerarn. Soc. 73(1990) 187.

[22] R. J. Price, J. Nucl. Mater. 33(1969) 17.

[23] Y. Seki, I. Yamauchi, K. Yamada and H. Kawasaki, J. Fusion Energy 3(1984) 241. 
FIGURE CAPTIONS

1. Reflected light optical micrographs of a SiC/SiC composite, a) transverse cross-section, b) longitudinal cross-section.

2. Thermal conductivity of a) $\mathrm{C} / \mathrm{C}$ and b) $\mathrm{SiC} / \mathrm{SiC}$ composite materials $(4,12)$.

3. Calculated effective thermal conductivities for $0 / 90$ fiber composites for $b / a=2$, a) transverse/transverse orientation, b) transverse-axial (15).

4. A comparison of the surface thermal stress limits for a range of materials (16).

5. Transition pressures for SiC active-passive oxidation vs temperature, according to G':lbransen and Jansson (17).

6. Oxidation resilts for uncoated $\mathrm{SiC} / \mathrm{C}$ and $\mathrm{C} / \mathrm{C}$ composites at $815^{\circ} \mathrm{C}$ in air.

7. Thermodynamic analysis of $\mathrm{SiC}+5 \% \mathrm{H}_{2} / \mathrm{Ar}$ at $1300^{\circ} \mathrm{C}$. Al1 pressures are in atmospheres (18). 
8. Phase diagram for the $\mathrm{SiO}_{2}-\mathrm{Li}_{2} \mathrm{O}$ system.

9. Crack velocity as a function of applied $K$ for SiC/SiC fiber composites tested at $1100^{\circ} \mathrm{C}$ with carbon fiber/matrix interfaces.

10. Calculated crack velocities for a crack with a fixed bridging zone length. Fiber pinching forces relaxed $5 \%$ and $50 \%$ to simulate time dependent fiber or fiber matrix interface creep.

11. Expansion of $\beta-\mathrm{SiC}$ as a function of fast neutron fluence at 625 to $1500^{\circ} \mathrm{C}(22)$.

12. Irradiation response of reaction-bonded $\mathrm{SiC}$ as a function of irradiation fluence, a) Youngs modulus and b) fracture strength (22).

13. Schematic of a load-deflection curve for ceramic matrix composites.

14. Gamma ray intensity behavior of carbon fiber/SiC composite after irradiation to $10 \mathrm{MW}-\mathrm{y} / \mathrm{m}^{2}$. The dashed 1 ine shows a safe surface dose rate of $2.5 \mathrm{mrem} / \mathrm{h}$ for the first walt (23). 
m

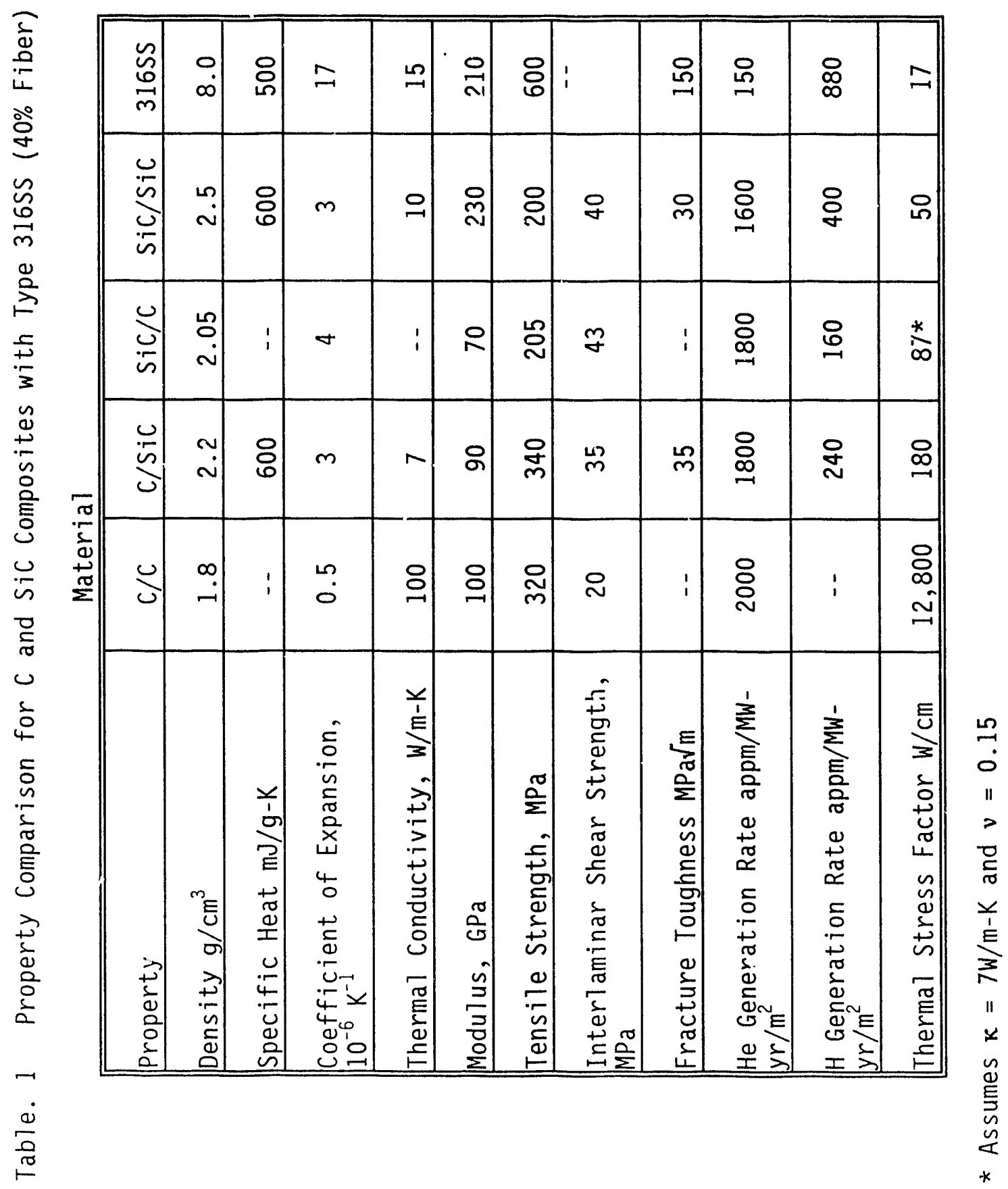




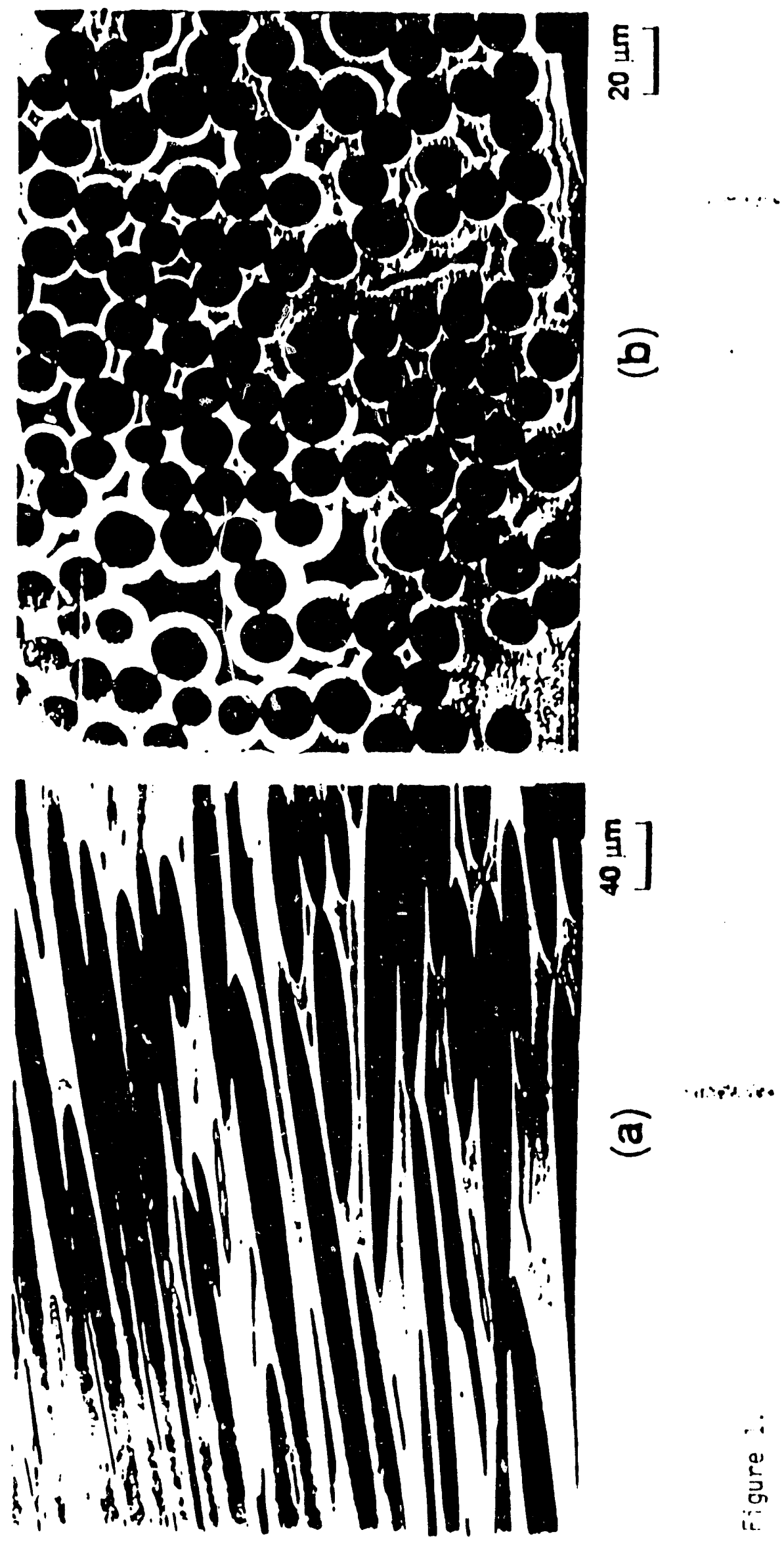



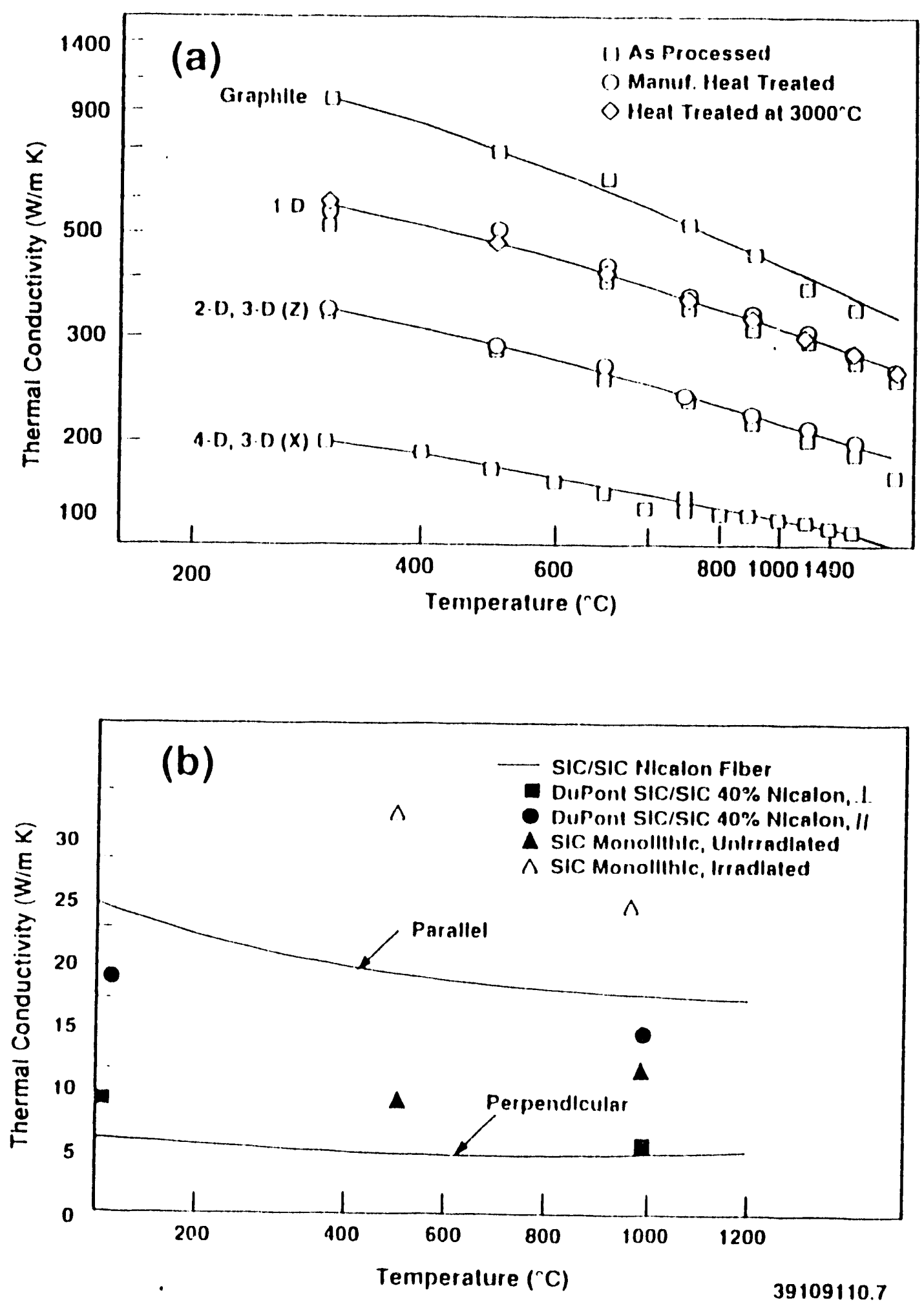

rigure 2. 

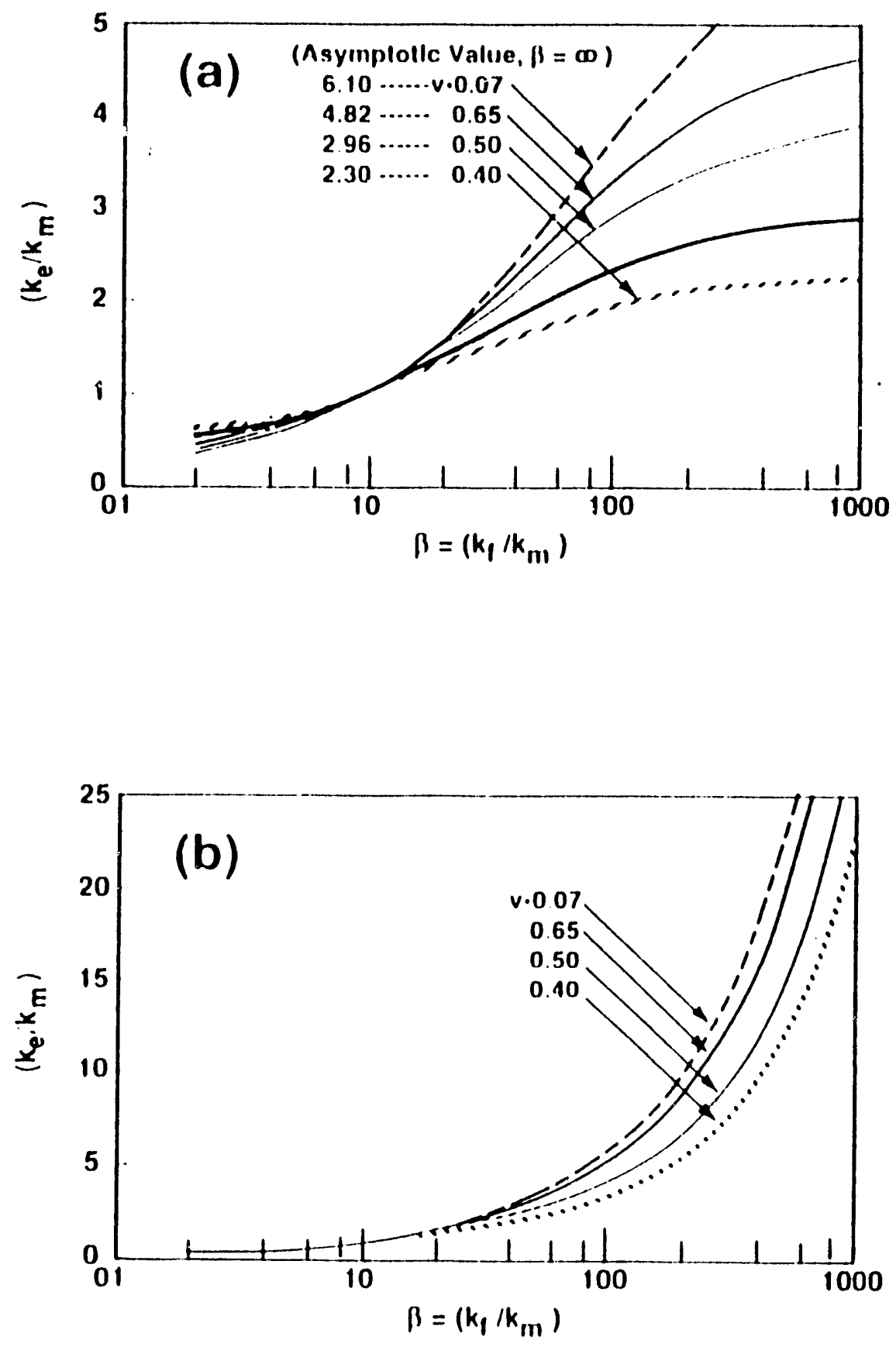

39109110.6

rigure 3. 


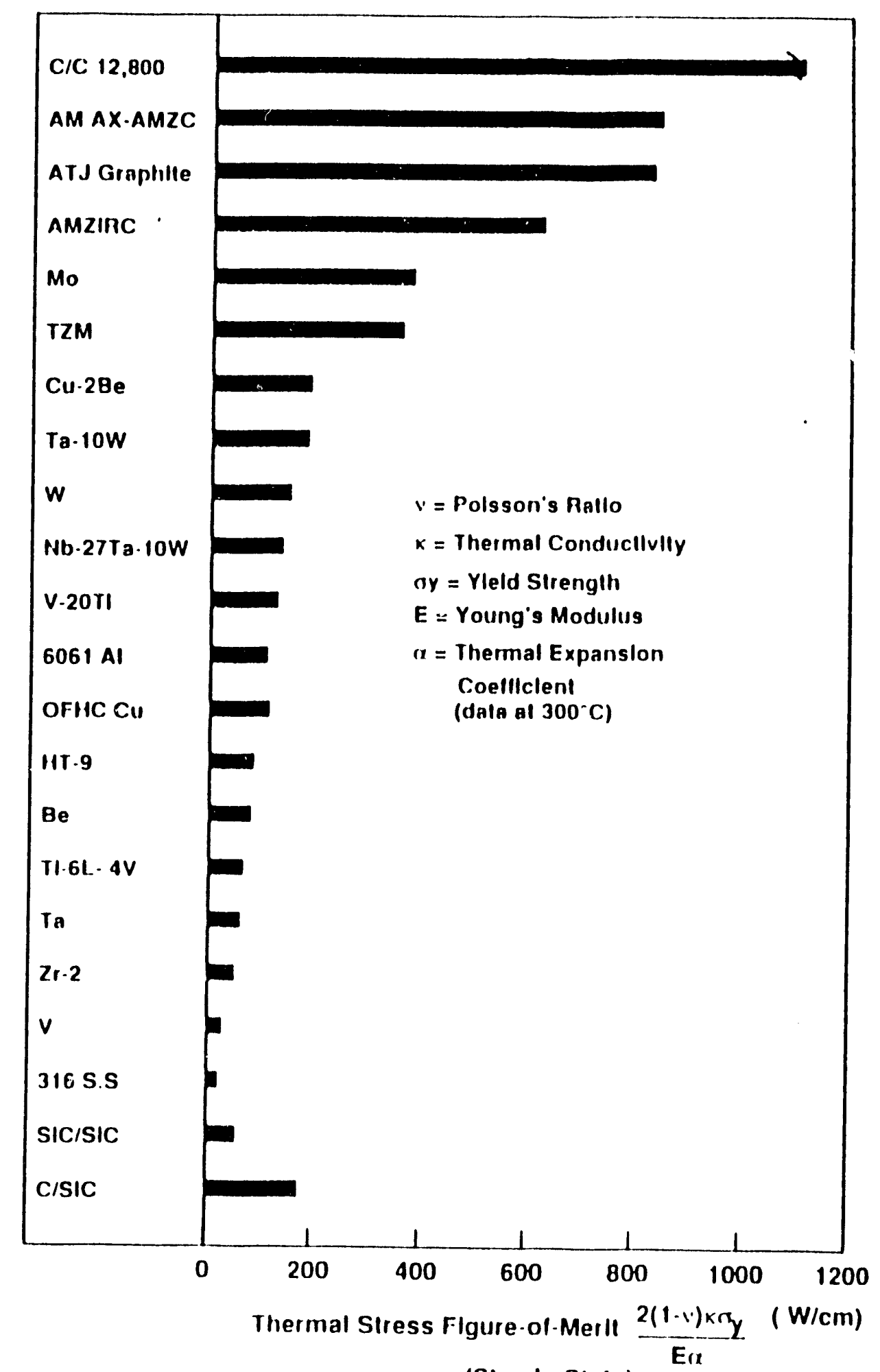

(Sleady-State)

39109110.8

rigure 1. 

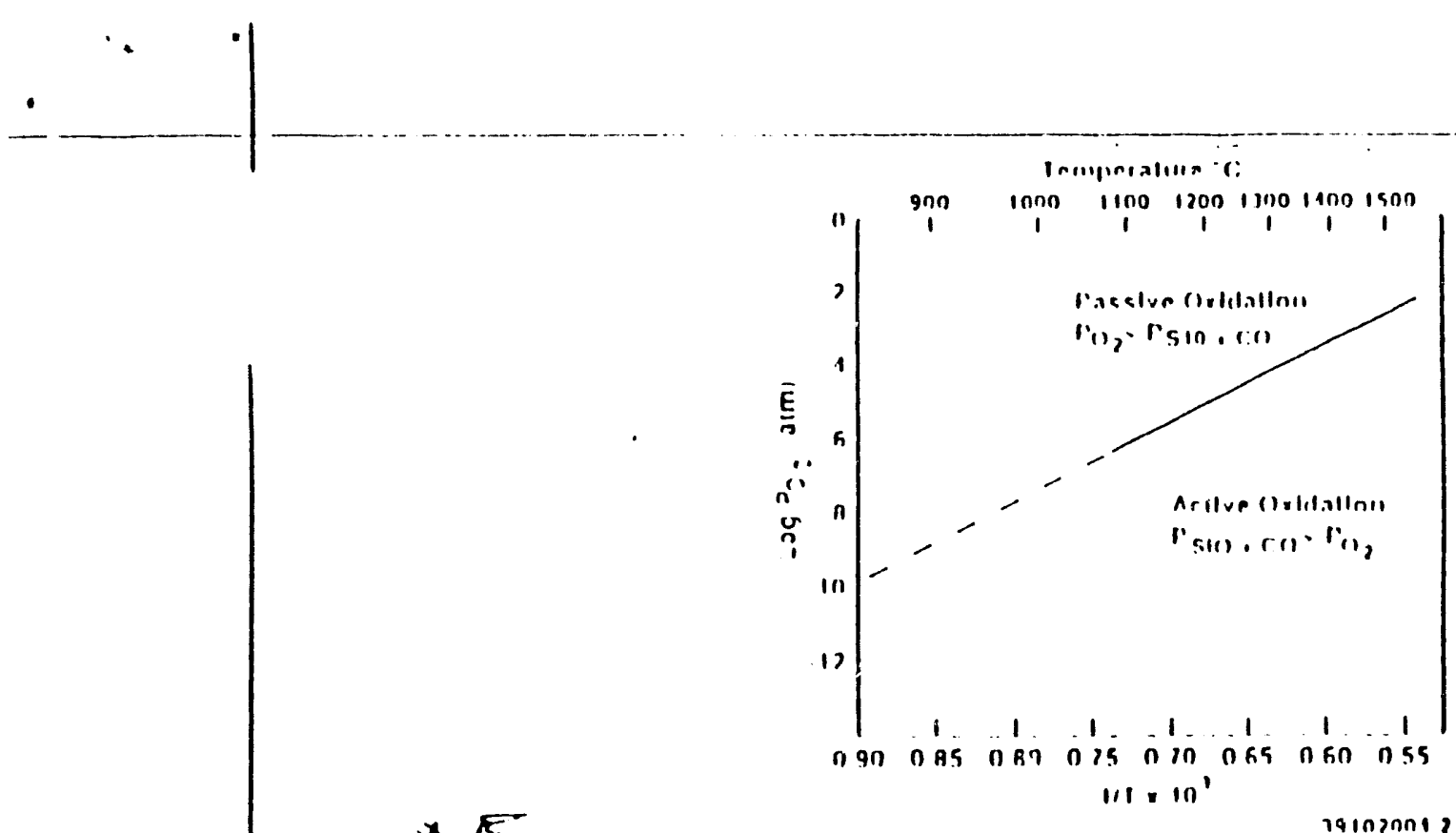

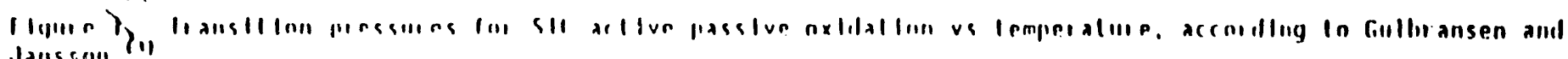

\section{$\$ .5$}




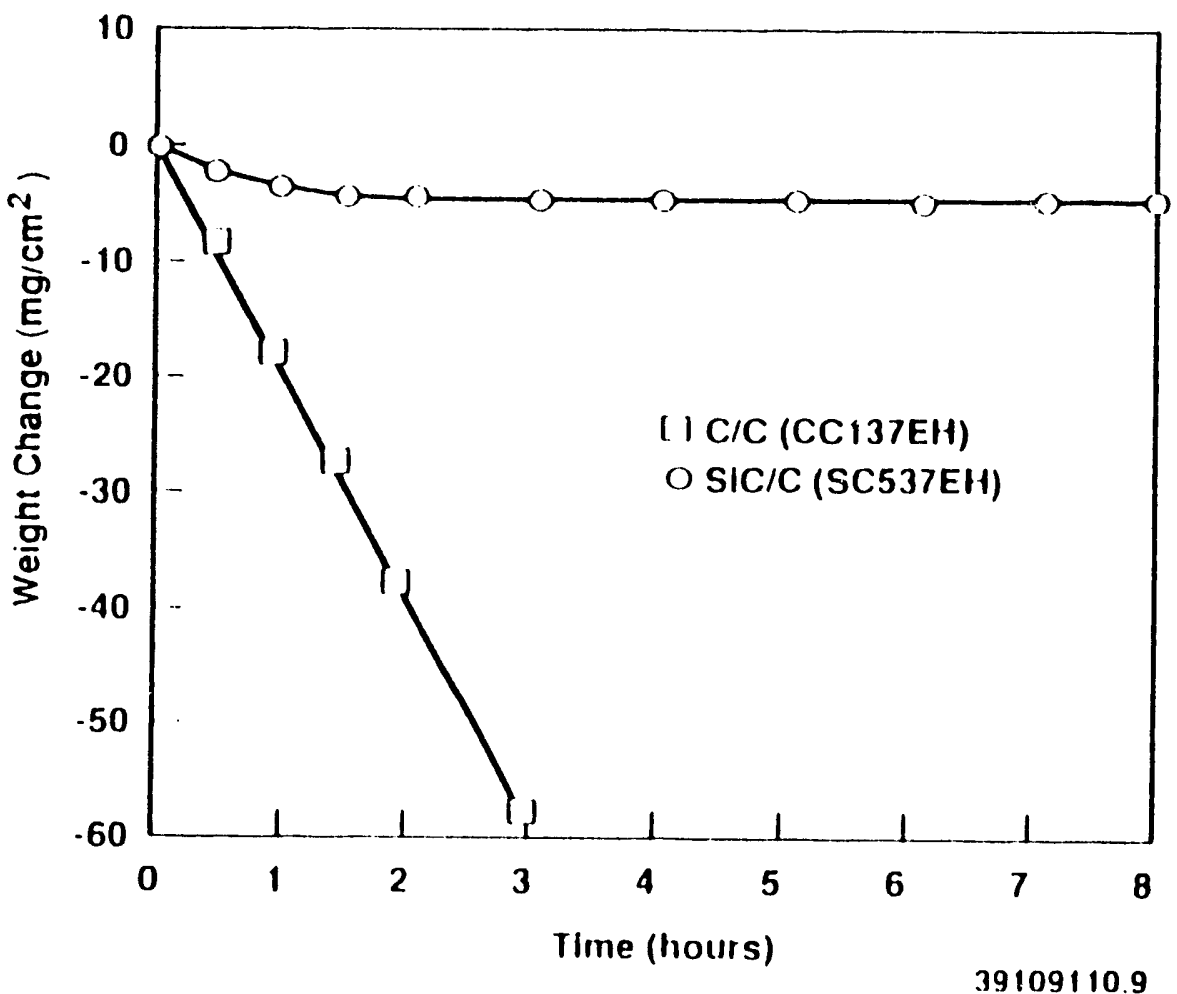

rigure 6. 


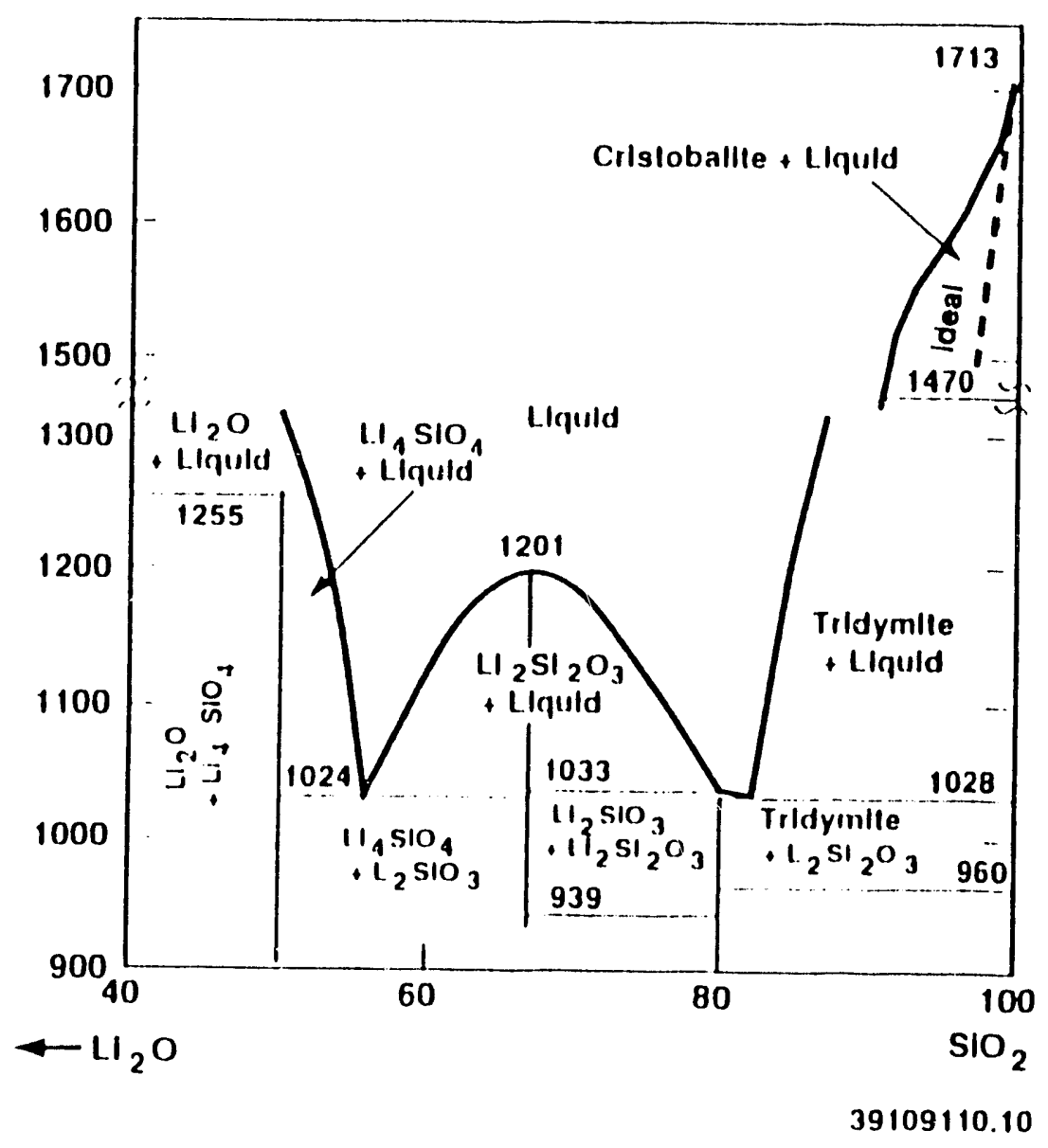

rigure 8. 


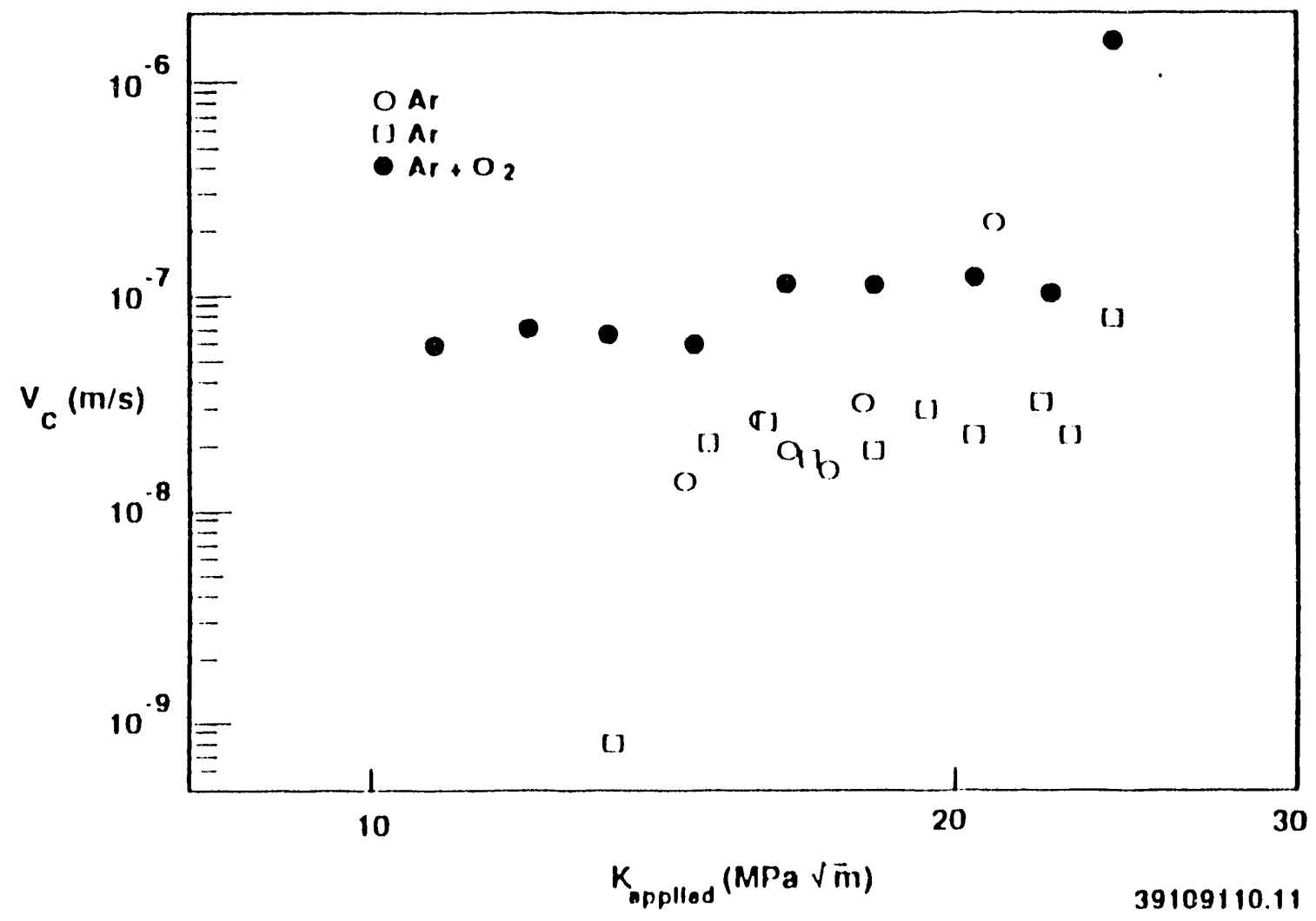

Finure 9. 


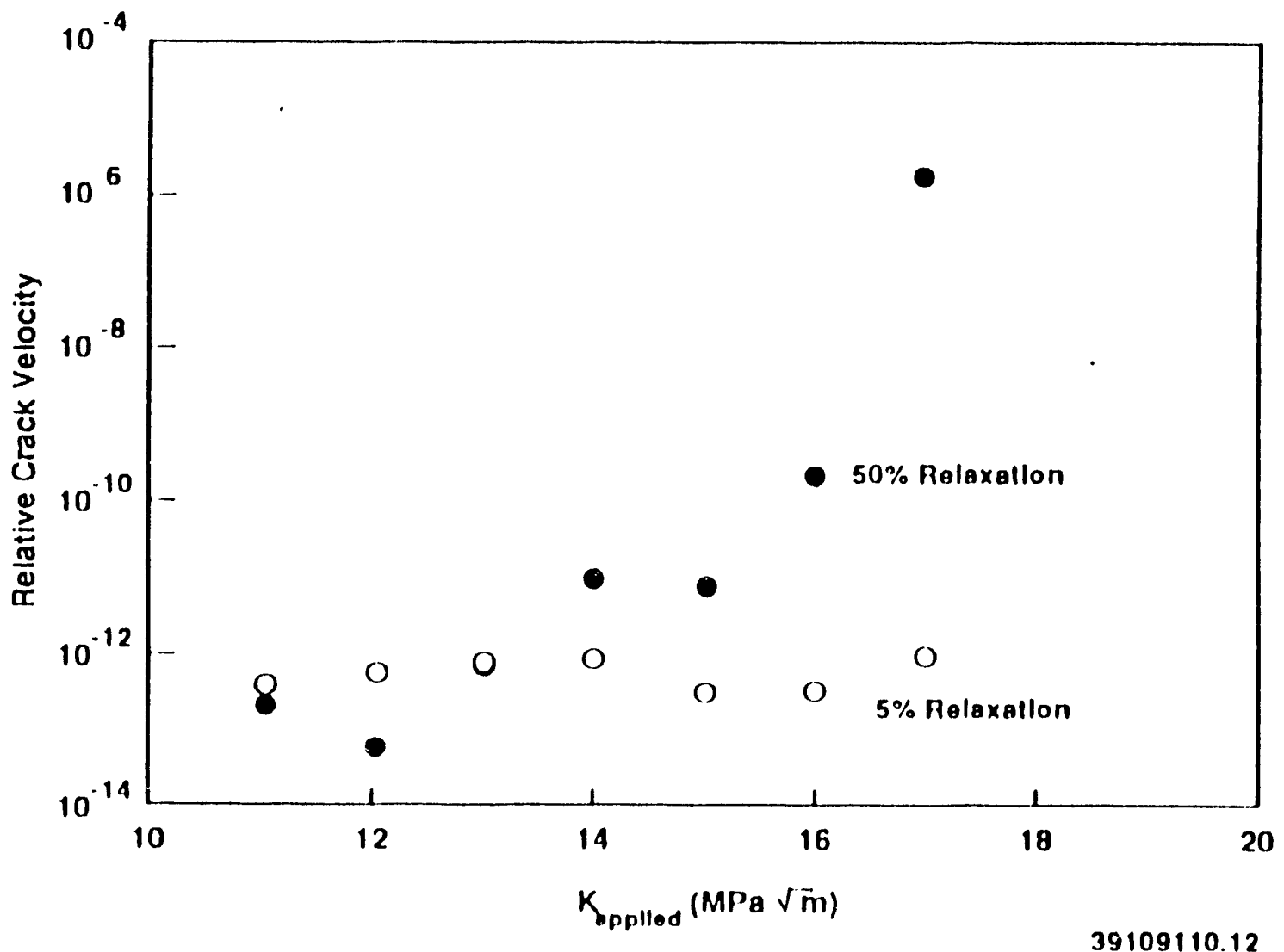

Figure 10. 


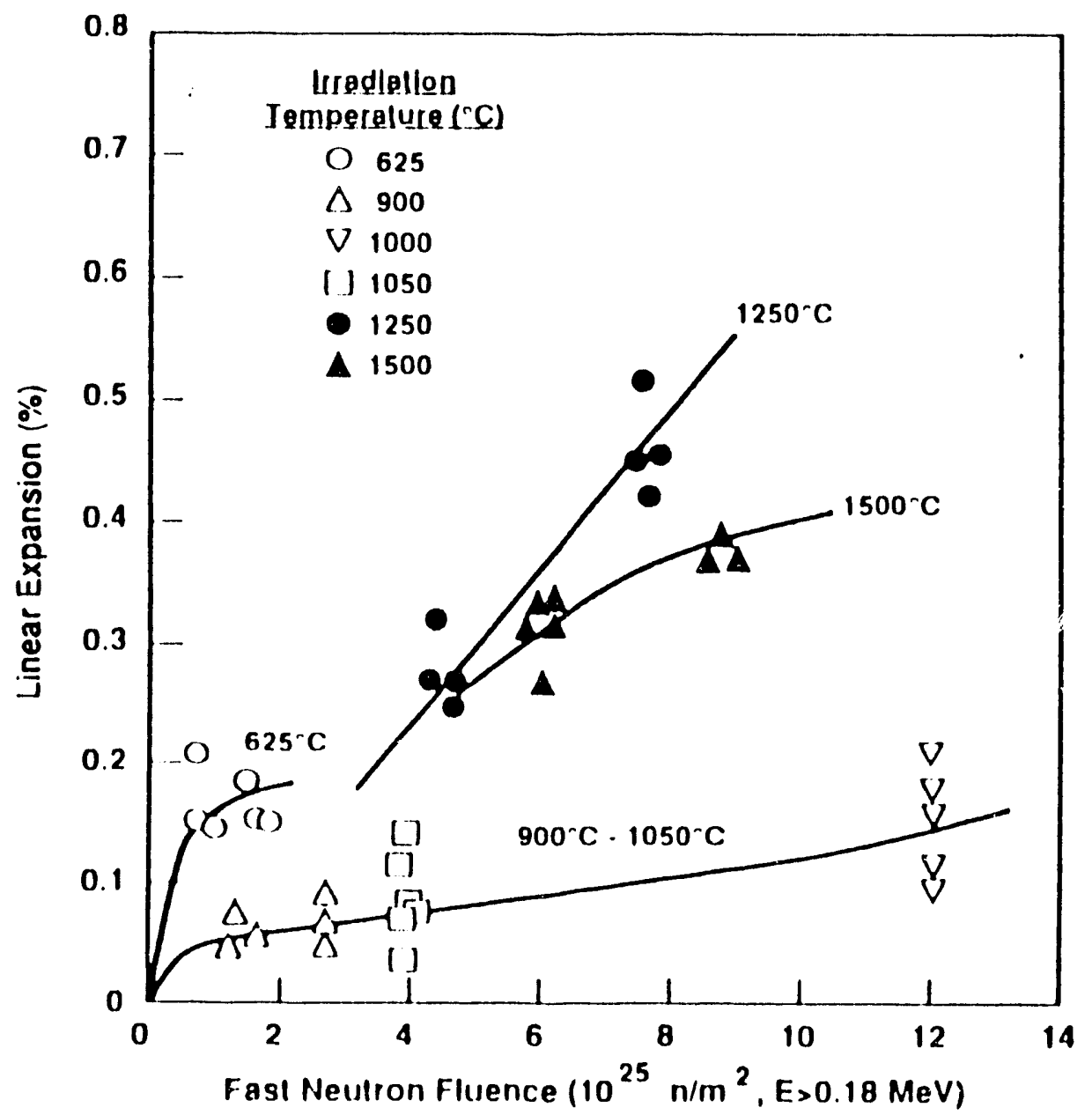

39109110.13

rigure 11. 

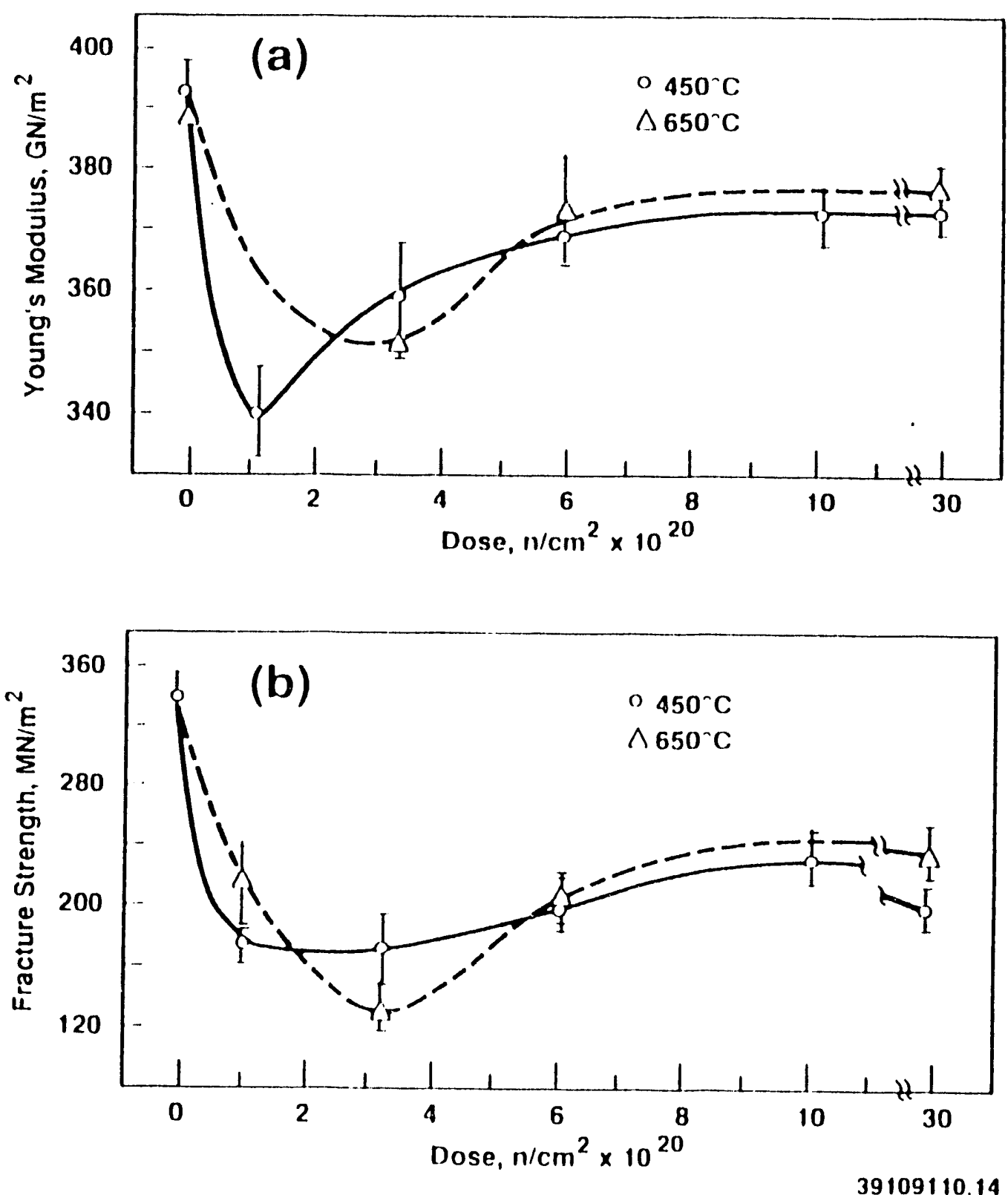

rigure 1? 


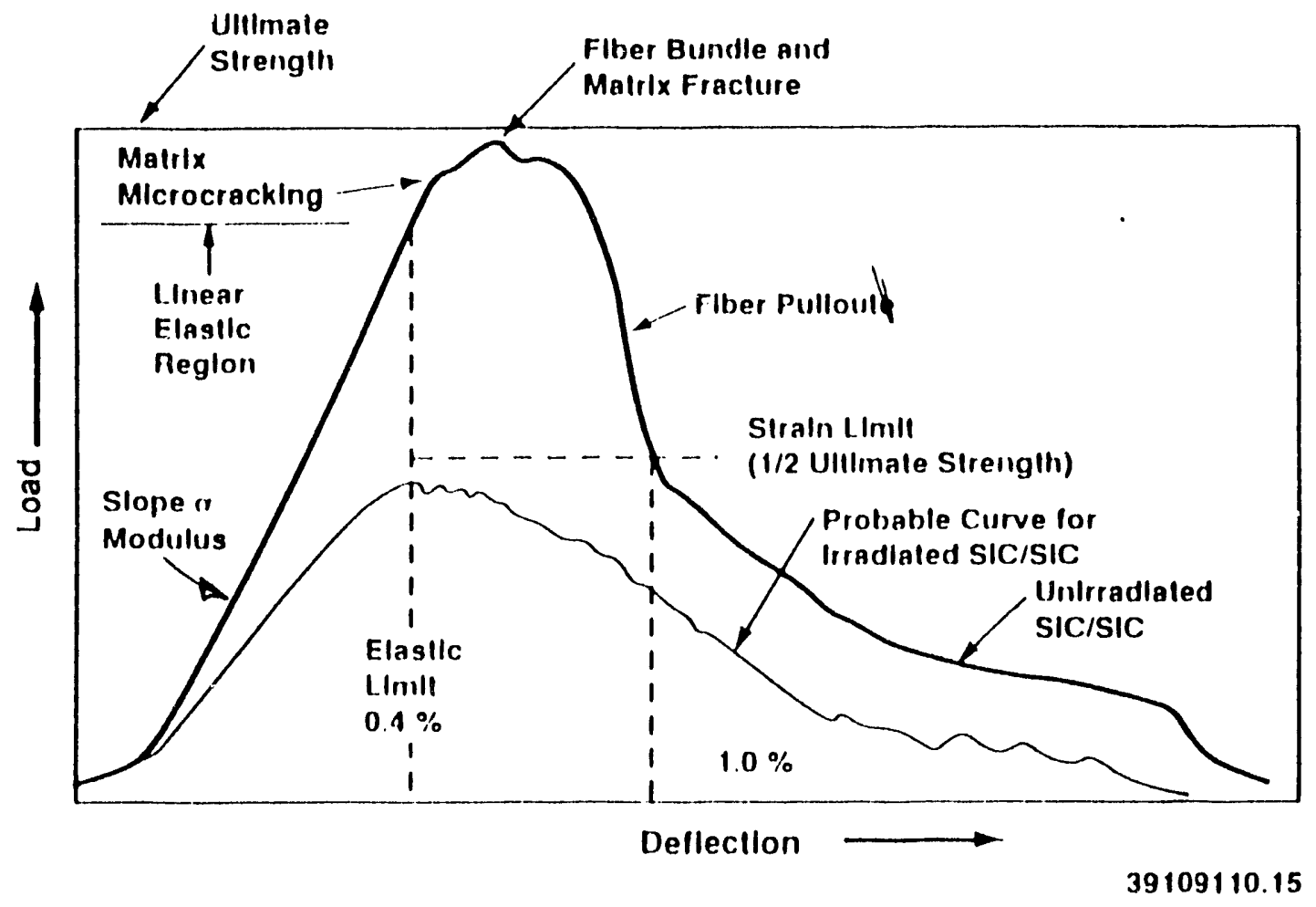

Figure 13. 


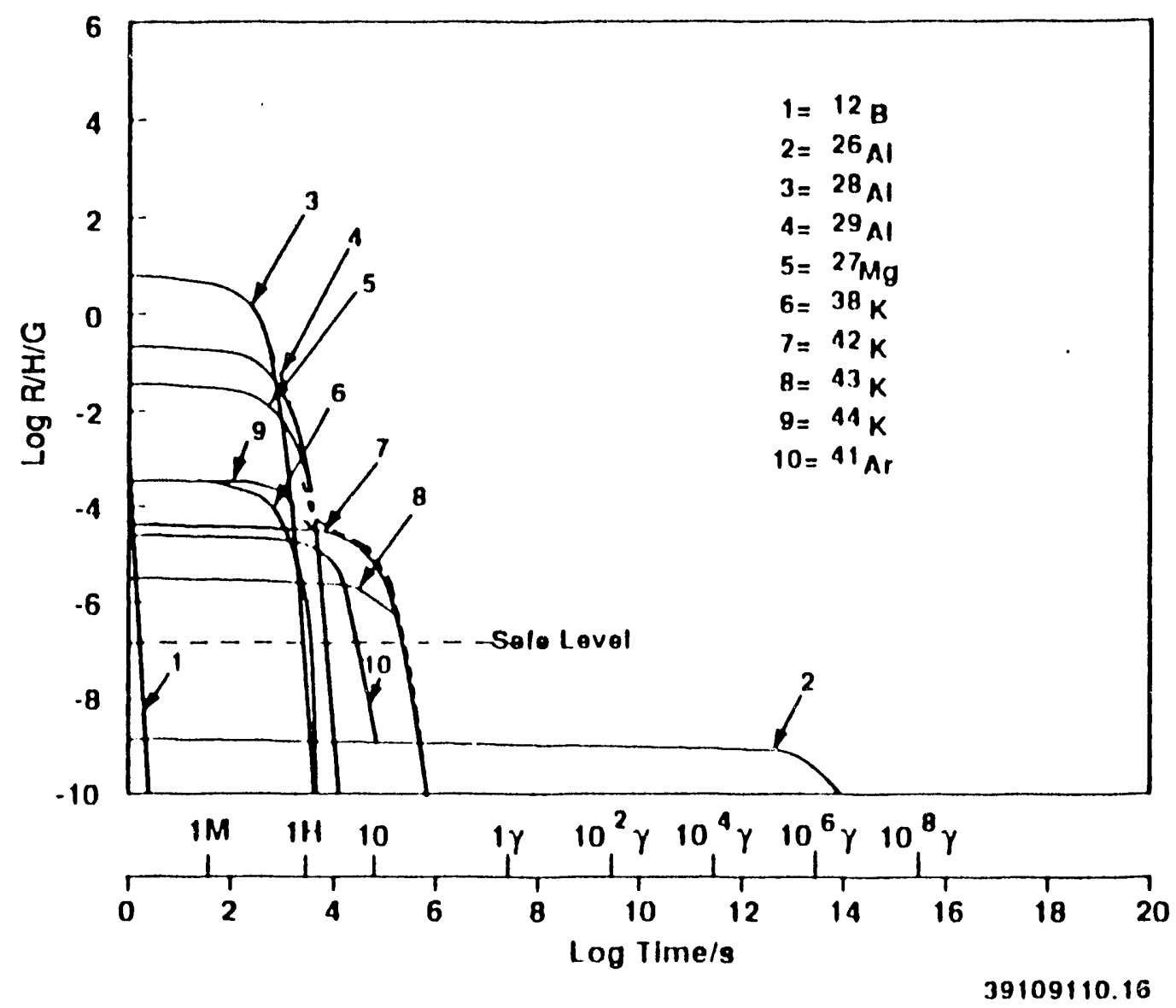

Figure 11. 

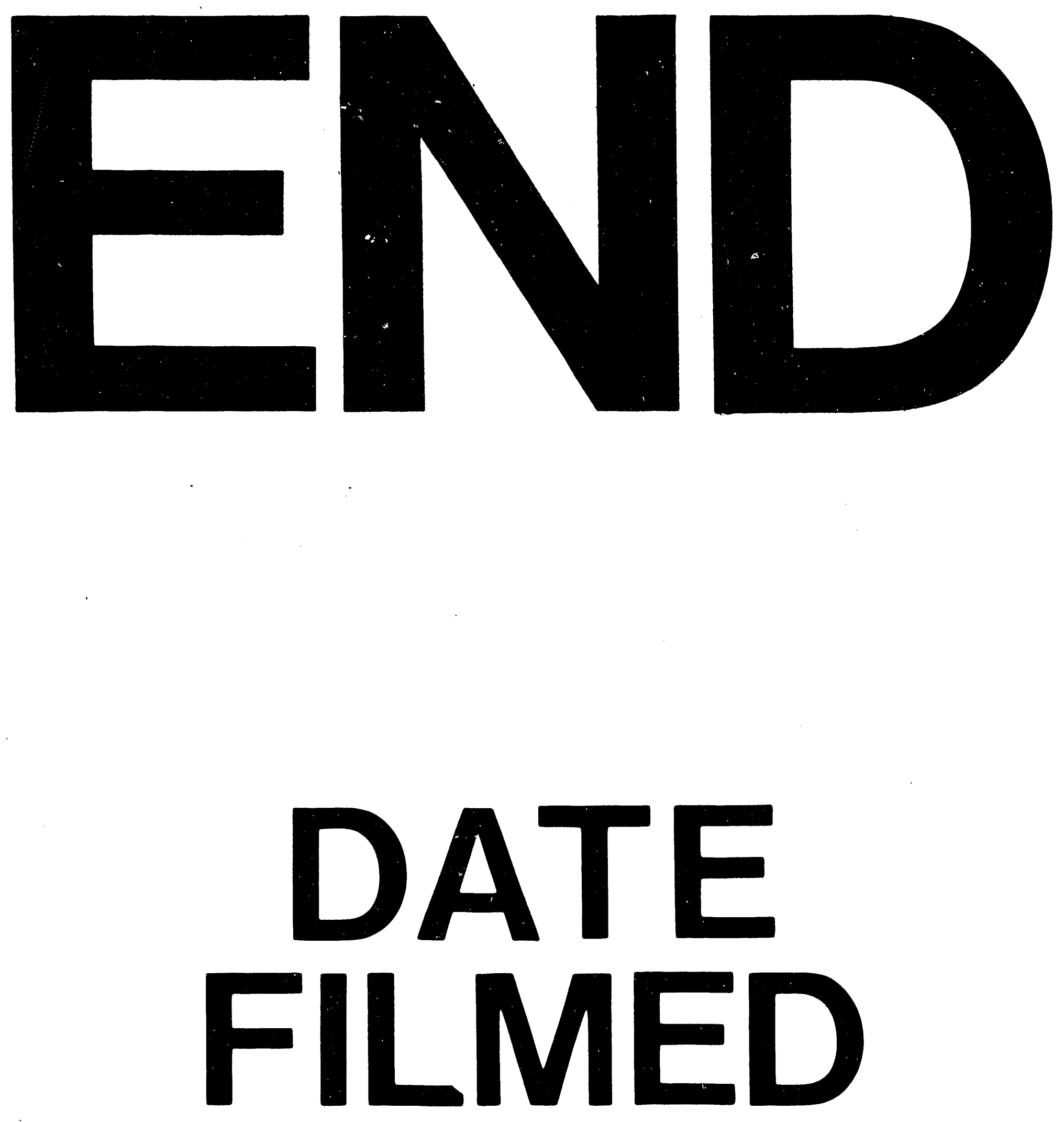

1

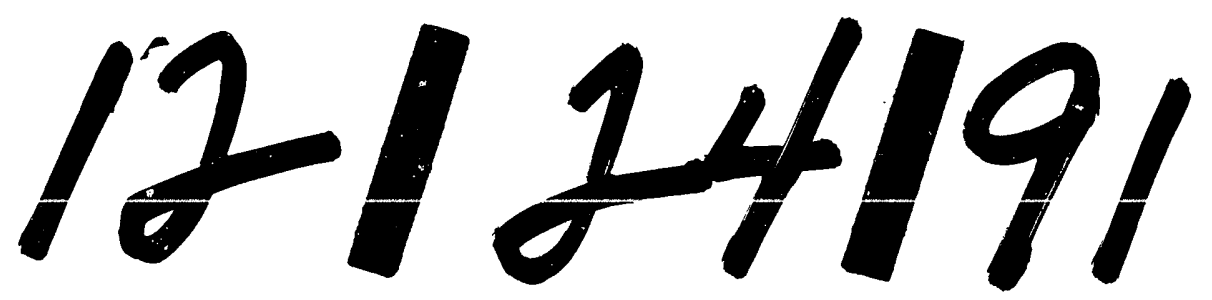




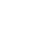

